\title{
Corrigendum
}

\section{Ethnicity and baseline symptomatology in patients with an At Risk Mental State for psychosis - Corrigendum}

doi:10.1017/S0033291711001486. Published by Cambridge University Press, 11 August 2011.

E. Velthorst, D. Nieman, W. Veling, R. Klaasen, S. Dragt, J. Rietdijk, H. Ising, L. Wunderink, D. Linszen, L. De Haan and M. van der Gaag

In this paper an incorrect range for items of the BDI-II was used (i.e. 1-4 instead of 0-3) for which the authors apologize. This means that the mean scores in Tables 2 and 3 should be 21 points less than those presented.

In Table 2, the correct mean BDI-II scores should read: 24.7 (13.1), 19.4 (11.3).

In the note to Table 2 , the range should read: BDI-II sum score (0-63).

In Table 3, the correct BDI-II scores should read: 19.4 (11.3), 27.9 (11.0), 32.2 (12.5), 17.7 (13.6), 19.1 (13.5), 25.6 (12.0).

\section{Reference}

Velthorst E, Nieman D, Veling W, Klaasen R, Dragt S, Rietdijk J, Ising H, Wunderink L, Linszen D, De Haan L, van der Gaag M (2011). Ethnicity and baseline symptomatology in patients with an At Risk Mental State for psychosis. Psychological Medicine. doi:10.1017/S0033291711001486. 